\title{
Heat Pipe and Thermosyphon for Thermal Management of Thermoelectric Cooling
}

\author{
Thiago Antonini Alves, Larissa Krambeck and \\ Paulo H. Dias dos Santos \\ Additional information is available at the end of the chapter
}

http://dx.doi.org/10.5772/intechopen.76289

\begin{abstract}
The heat pipe and thermosyphon are passive heat transfer devices with phase change, which can be applied for thermal management of thermoelectric cooling, such as the TEC hot side. The heat pipes basically consist of a metal tube sealed with capillary structure internally that is embedded with a working fluid. This capillary structure can be made of screen meshes, grooves, or sintered media. The thermosyphon is a heat pipe assisted by gravity, because it has no capillary structure. Then, in this chapter, manufacturing of low cost and easy-to-manufacture heat pipes and thermosyphon is described in detail, and an experimental evaluation of their thermal performance is accomplished. The considered devices were a rod, a thermosyphon, a mesh heat pipe, a grooved heat pipe, and a sintered heat pipe. According to the behavior of the global thermal resistance and the effective thermal conductivity, the passive devices operated satisfactorily with the exception of the rod and the thermosyphon in the horizontal position. The heat pipes were the best among the tested devices and the best position was vertical.
\end{abstract}

Keywords: heat pipe, thermosyphon, thermoelectric, thermal management, experimental thermal performance, TEC

\section{Introduction}

Nowadays the advance in the development of computer systems has helped the science to find out computational solutions on understanding phenomena inherent to the problems faced by engineering [1]. The increase of computer system performance has resulted in a high heat generation. On the other hand, the computers' performance can be potentially reduced 
due to these high heat flux densities [2]. Therefore, the thermal management of this kind of electronic equipment has become a challenge in order to avoid the overheating and, as a consequence, the hardware failure [3].

According to Sun et al. [4], passive cooling systems such as air, liquid, and heat exchangers with phase change are used to regulate the temperature of CPU and other electronic components at desired levels. Nevertheless, these traditional passive cooling systems are restricted to the working fluid limitations. In this scenario, the thermoelectric cooling (TEC) system can be considered as an alternative to the thermal management of CPU and other electronic components.

A TEC system is composed of a thermoelectric module, a cold, and a hot region. Thermoelectric modules work under the Peltier effect when a DC current passes through a cell made of semiconductor materials; one of the junctions is cooled while the other is heated. In general, the cold region of TEC can be used for cooling the components of personal computers, CPU, graphics processors, and so on. However, its cooling performance is restricted by the thermal resistance at TEC hot region. Besides, TEC is attractive for cooling these devices due to its low weight, compact size, and vibration free characteristics [5].

In order to improve the TEC cooling performance, the heat pipes or thermosyphons can be used as an alternative for TEC hot side cooling [6]. A schematic diagram of a TEC/Heat Pipes (or thermosyphons) system coupled to CPU is shown in Figure 1. The principle of this technology is: the heat generated in CPU is transferred to the TEC cold region, where the conversion of electrical energy into thermal energy occurs by Peltier effect, and after this process, the

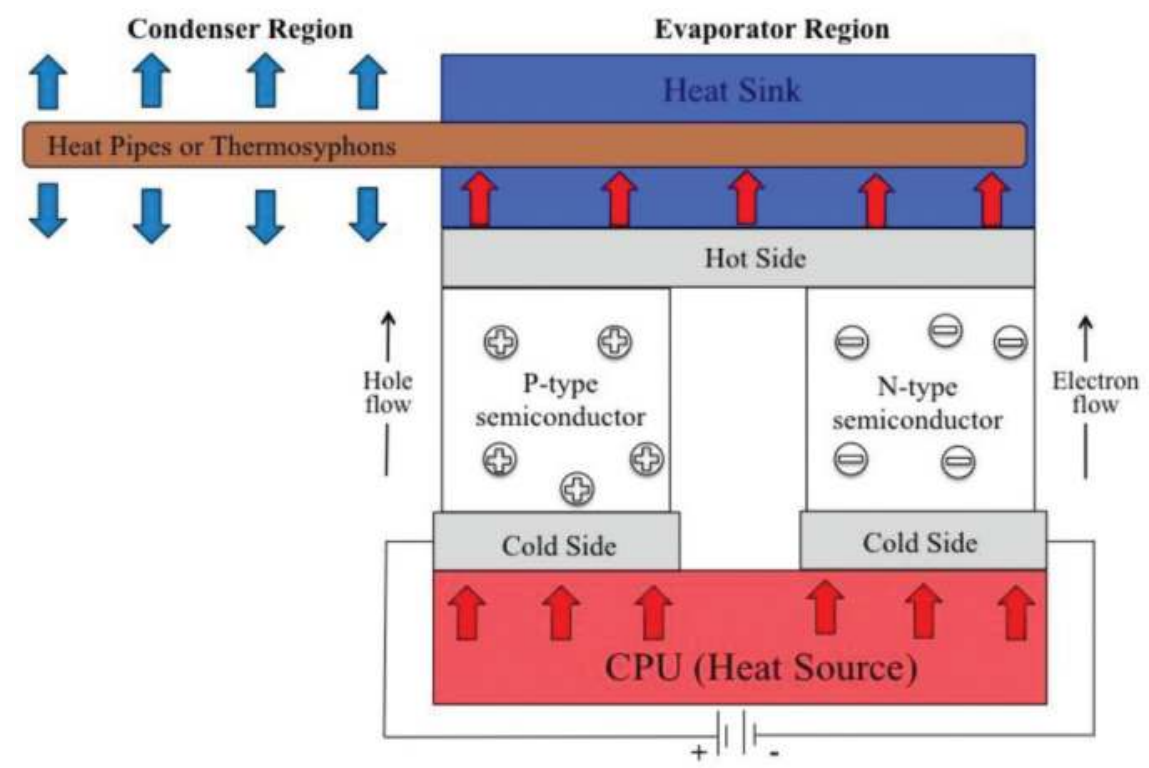

Figure 1. Schematic diagram of a TEC/heat pipes (or thermosyphons) system coupled to CPU. 
heat is transferred to the TEC hot side. In order to increase the TEC hot side cooling, a heat dissipation system is used, which is composed of a heat sink and heat pipes (or thermosyphons). Thus, the evaporators of heat pipes (or thermosyphons) are fixed in the heat sink and absorb the heat generated by CPU and transfer this heat to the condensers of the heat pipes (or thermosyphons), where finally it is dissipated to the environment.

Heat pipes and thermosyphons are passive heat transfer devices capable of transferring large amounts of heat with a small temperature difference. They became popular in recent decades because of their effectiveness and convenience. These devices are used to improve heat transfer in many industrial fields such as electronics, telecommunications, aerospace, among others [7]. The heat transmitted through these devices is based on phase change. Major advantages of heat pipes include a very high thermal conductance, no pumping power requirements, no moving parts, and relatively low-pressure drops [8]. Furthermore, the heat pipes and thermosyphons are devices relatively simple to manufacture and, therefore, have low cost when their geometry is favorable [9].

The heat pipes and thermosyphons operate according to the following principle [10]: in the evaporator region, heat is transferred to the heat pipe or thermosyphon, vaporizing the working fluid contained inside this region. The steam generated is moved, due to the pressure and density differences, to the cooling regions of the heat pipe or thermosyphon (condenser region) where heat transported is rejected to the cold source. In the heat rejection process, the steam condenses, and the condensate returns back to the evaporator closing the cycle. The adiabatic region, which may have variable dimensions (in some cases it is absent), is located between the evaporator and the condenser being insulated from the external environment. In the heat pipes, the working fluid returns from the condenser to the evaporator due to capillary pumping effect while in the thermosyphon the working fluid returns exclusively by gravity because it has no capillary structure. A schematic diagram of the operating principle of heat pipes is presented in Figure 2 [11]. More details on the principle of the heat pipes and thermosyphons can be found in [7-10].

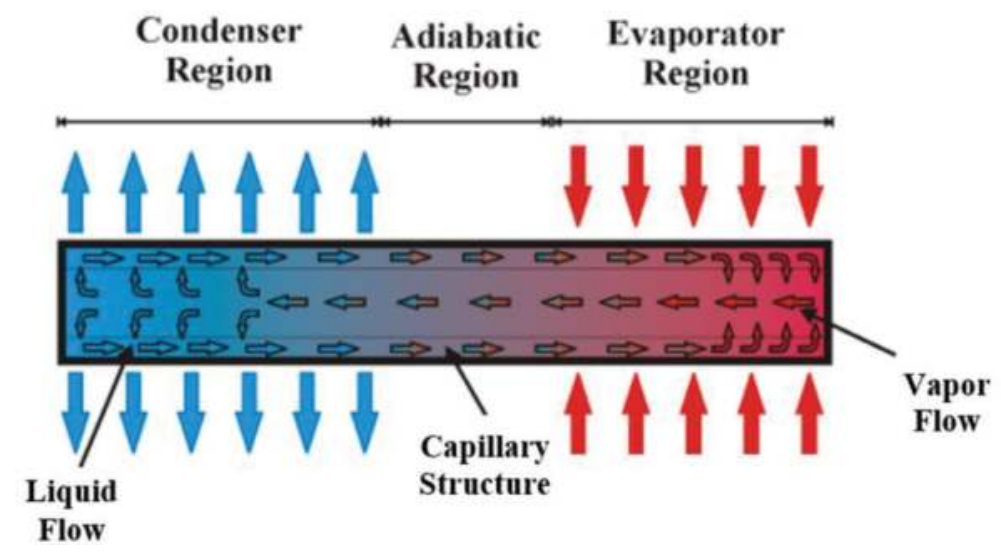

Figure 2. Sketch of the operating principle of a heat pipe [11]. 
The heat pipes basically consist of a metal tube sealed with capillary structure internally, which is embedded with a working fluid [12]. This capillary structure can be made of screen meshes, grooves, or sintered media [13]. The metal screen is the most commonly used capillary structure because of availability, ease of construction and good capillary pumping [14]. The grooves, as capillary structure, have a high thermal conductivity and good permeability [15]. The sintered metal wicks are manufactured by packing tiny metal particles between the inner heat pipe wall and a mandrel in powder form [16]. As mentioned earlier, the thermosyphon is a heat pipe assisted by gravity, which means that it has no capillary structure to return the working fluid [17]. Some researches available in the literature about thermal management of thermoelectric cooling used heat pipes and thermosyphons $[4,5,18-20]$.

Thus, in this chapter, manufacturing of low cost and easy-to-manufacture heat pipes and thermosyphon is described in detail, and an experimental evaluation of the thermal performance is accomplished for several different passive devices that can be used for thermal management of thermoelectric cooling. The considered devices were a rod, a thermosyphon, a mesh heat pipe, a grooved heat pipe, and a sintered heat pipe. In order to evaluate the best passive heat transfer device, their thermal performance was compared.

\section{Heat pipe and Thermosyphon manufacturing}

In this section, each step of a heat pipe and a thermosyphon manufacturing is described in detail. The proposed procedure has low-cost and the heat transfer passive devices are easyto-manufacture. The steps are cleaning, assembly, tightness test, evacuation procedure, and filling with the working fluid. These procedures were based on [21-26].

If the operation conditions are favorable to gravity, a thermosyphon can be manufactured. As a result, a capillary structure is not necessary. However, in adverse conditions, a wick should be selected and accommodated in the involucre inner. As mentioned before, the capillary structures can be screen meshes, grooves, sintered powder, among others.

The involucre material, capillary structure (if applicable), and the working fluid depend on the application, and they need to be chemically and mechanically compatible. For thermoelectric cooling, the operation temperature is around $150^{\circ} \mathrm{C}$, which makes suitable to use copper and distilled water for involucre and working fluid, respectively.

First of all, the main components of the heat pipe or the thermosyphon have to be prepared. The sintered heat pipe involucre consists of the casing, the closing lids, and the capillary, as shown in Figure 3.

\subsection{Cleaning process}

The cleaning of the heat pipe or the thermosyphon is necessary to ensure the working fluid wettability, the impurity elimination, and the vacuum quality improvement [27]. Consequently, 
the heat pipe or thermosyphon components need to be thoroughly cleaned, before the introduction of the working fluid. For this purpose, first, the casing, the closing lids, the capillary, and the capillary structure (if applicable) are cleaned with acetone in order to remove larger dirties. Then, they are thoroughly cleaned with a sulfuric acid solution $\left(\mathrm{H}_{2} \mathrm{SO}_{4}\right.$ of $\left.0.1 \mathrm{M}\right)$. After that, these components are taken to an ultrasonic bath, where they remained immersed in acetone for $30 \mathrm{~min}$. Finally, the cleaning is completed. Figure 4 shows the cleaning of the sintered heat pipe components in an ultrasonic bath.

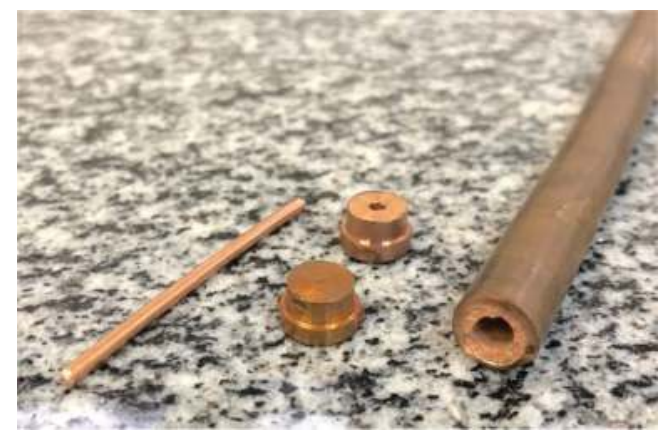

Figure 3. Sintered heat pipe components.

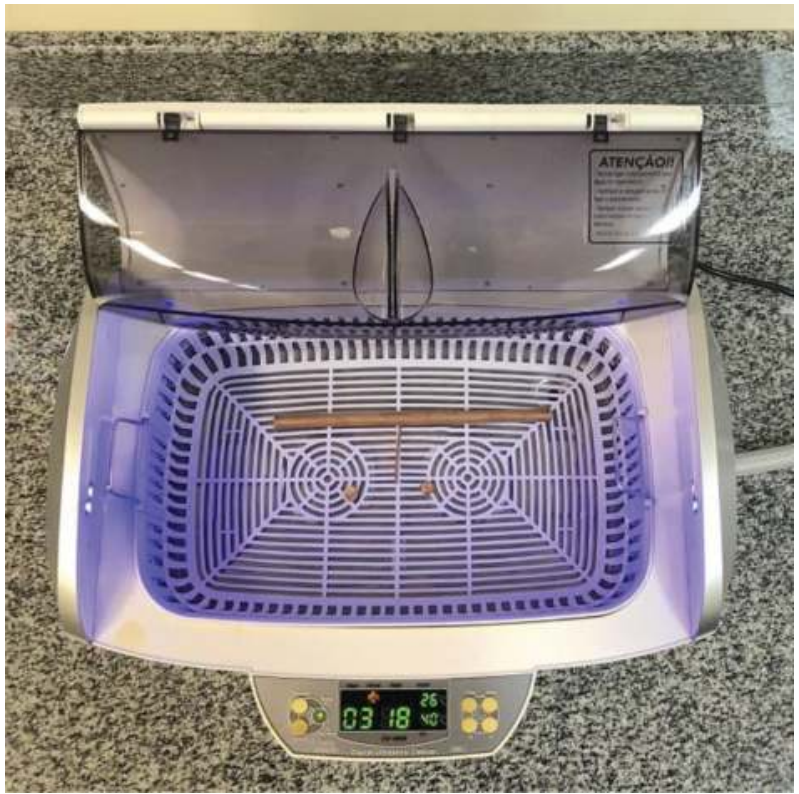

Figure 4. Cleaning procedure in the ultrasonic bath. 


\subsection{Assembling of the heat pipes and the thermosyphon}

After the cleaning process, the heat pipe or thermosyphon can be properly assembled. As the wick is inside the casing, the closing lids and the capillary are welded to the tube extremities (Figure 5). In the case of copper involucres, the welding process can be performed with the aid of a soldering iron and the parts can be brazed using a tin alloy as filler material.

\subsection{Tightness test}

A tightness test has to be conducted to verify if there was no flaw in the welding process of the heat pipe or thermosyphon. A manual positive displacement pump, a water container (e.g., a sink full of water), and a polymeric tube are necessary to accomplish a low-cost test (Figure 6). The polymeric tube makes the connection between the pump and the capillary tube. The heat pipe or thermosyphon is inserted into the water container and the air is pumped into the tube using the positive displacement pump. If there are any flaws in the solder, bubbles will appear in the water. In case of the presence of bubbles, the heat pipe or thermosyphon has to be disassembled, cleaned, welded, and retested.

\subsection{Evacuation procedure}

First, the heat pipe or thermosyphon is connected to a vacuum pump ( $\left.\mathrm{Lab} 1000^{\mathrm{TM}}\right)$ that can remove some residual liquid from the cleaning process. Then, the heat pipe or thermosyphon is linked to a vacuum pump EOS Value ${ }^{\mathrm{TM}} \mathrm{i} 260 \mathrm{SV}$ by a polymeric hose. This second pump will do the evacuation process, which the internal pressure should reach at least 90 mbar $(9 \mathrm{kPa})$ - Figure 7 . To make sure the connections do not leak, the polymeric hose is connected to the capillary with high vacuum grease Dow Corning ${ }^{\mathrm{TM}}$, prior to starting the vacuum process. The evacuation procedure has a duration of at least $8 \mathrm{~h}$. At the end of the procedure, the polymeric hose is sealed with the assistance of a forceps and the vacuum pump is turned off.

\subsection{Filling with working fluid}

The amount of working fluid inserted in the heat pipe or thermosyphon is essential for capillary pumping system because the heat transfer depends on that amount of fluid. If there is not enough fluid, the pumping system stop to work and the heat pipe or thermosyphon collapses and as a result, the transferring heat is ceased. As a result, the filling ratio should be carefully chosen. Usually, the filling ratio is based on the evaporator volume.

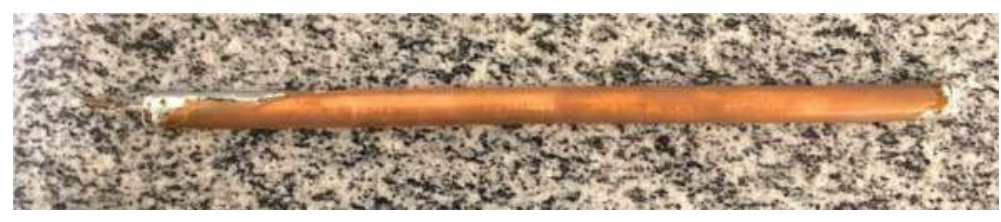

Figure 5. Assembled heat pipe. 
To perform the filling procedure with the working fluid, a small filling station has to be developed. The filling station is composed of a universal support, a graduated burette (scale of $0.1 \mathrm{~mL}$ ) with a capacity of $25 \mathrm{~mL}$, and a forceps (Figure 8). The burette and the polymeric hose are completely filled with the working fluid. The evacuated heat pipe or thermosyphon is coupled to the burette by the polymeric hose. Make sure that there are no air bubbles in the tube connecting the burette and the heat pipe or thermosyphon. The next step is to carefully open the burette valve. The forceps are carefully opened to drain the working fluid until the heat pipe or thermosyphon was charged with the correct quantity. It is emphasized that at the moment of filling, great care must be taken; otherwise, the heat pipe or thermosyphon vacuum will be lost. If this happens, the entire vacuum process must be performed again. After charging, the capillary is closed with grip pliers and the capillary end is welded to the completely sealing (Figure 9).

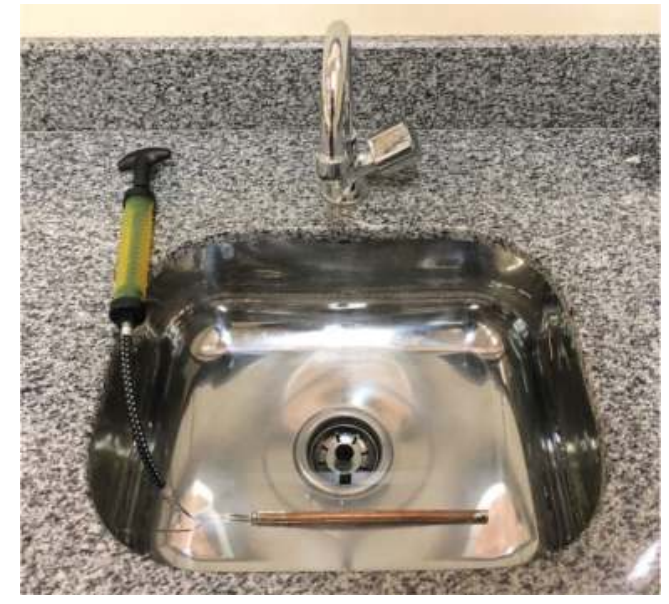

Figure 6. Low-cost tightness test.

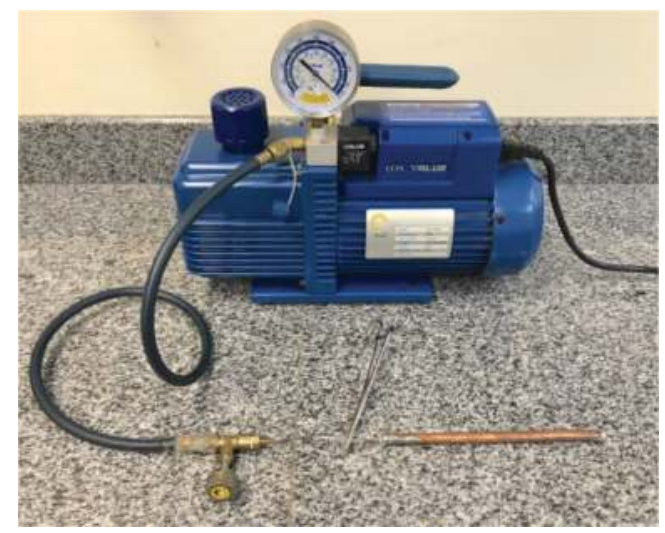

Figure 7. Evacuation procedure. 


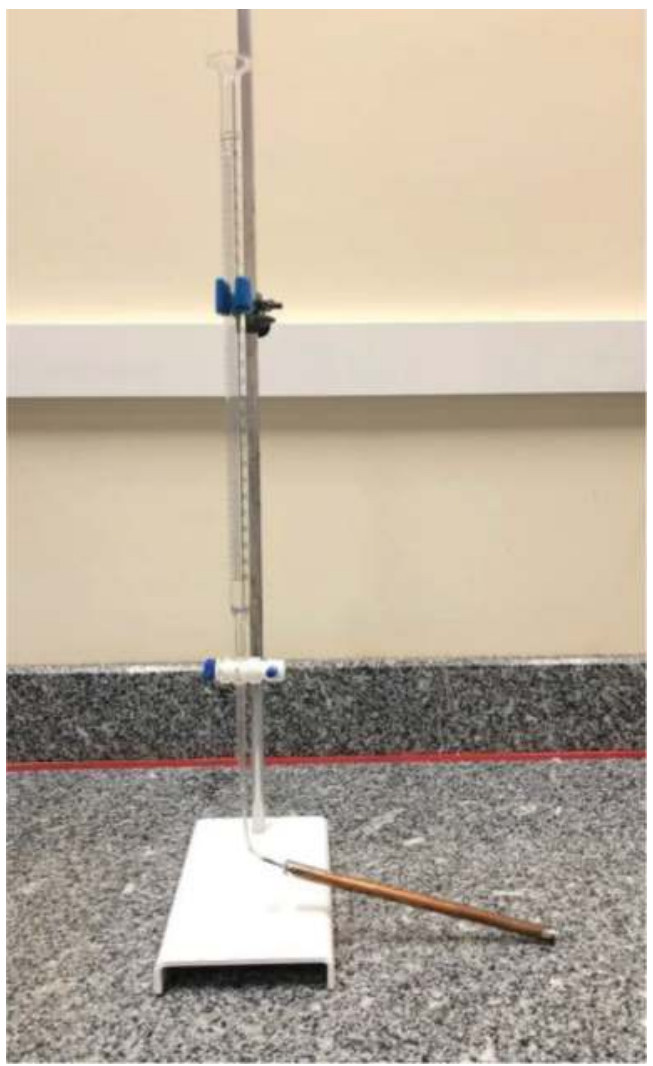

Figure 8. Filling station with the heat pipe.

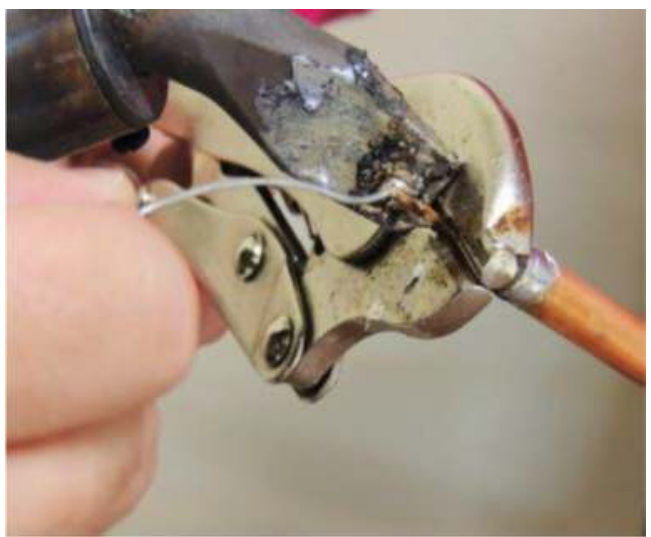

Figure 9. Welding the capillary end. 


\section{Characteristics of the developed passive devices}

The heat pipes and thermosyphon were produced by copper tubes ASTM B-75 Alloy 122 with an outer diameter of $9.45 \mathrm{~mm}$, an inner diameter of $7.75 \mathrm{~mm}$, and a length of $200 \mathrm{~mm}$. The rod was obtained from a full copper bar ASTM B-75 Alloy 122 with the same dimensions of the developed heat pipes and thermosyphon. All the devices had an evaporator of $80 \mathrm{~mm}$

\begin{tabular}{|c|c|c|c|c|c|}
\hline \multirow[t]{2}{*}{ Characteristics } & \multirow[t]{2}{*}{ Rod } & \multirow[t]{2}{*}{ Thermosyphon } & \multicolumn{3}{|l|}{ Heat Pipe } \\
\hline & & & Mesh & Grooved & Sintered \\
\hline Inner diameter [mm] & - & 7.75 & 7.75 & 6.20 & 7.75 \\
\hline Outer diameter [mm] & 9.45 & 9.45 & 9.45 & 9.45 & 9.45 \\
\hline $\begin{array}{l}\text { Evaporator length } \\
\text { [mm] }\end{array}$ & 80.0 & 80.0 & 80.0 & 80.0 & 80.0 \\
\hline $\begin{array}{l}\text { Adiabatic section } \\
\text { length }[\mathrm{mm}]\end{array}$ & 20.0 & 20.0 & 20.0 & 20.0 & 20.0 \\
\hline $\begin{array}{l}\text { Condenser length } \\
{[\mathrm{mm}]}\end{array}$ & 100 & 100 & 100 & 100 & 100 \\
\hline Working fluid & - & Water & Water & Water & Water \\
\hline $\begin{array}{l}\text { Volume of working } \\
\text { fluid [mL] }\end{array}$ & - & 2.26 & 2.19 & 1.73 & 2.26 \\
\hline Filling ratio [\%] & - & 60 & 60 & 60 & 80 \\
\hline Capillary structure & - & $\begin{array}{l}\text { No capillary } \\
\text { structure }\end{array}$ & $\begin{array}{l}\text { Phosphor bronze } \\
\text { screen mesh \#100 }\end{array}$ & $\begin{array}{l}\text { Microgrooves by the } \\
\text { wire-EDM }\end{array}$ & $\begin{array}{l}\text { Copper powder } \\
\text { sintered }\end{array}$ \\
\hline
\end{tabular}

Table 1. Main features of the heat transfer passive devices.

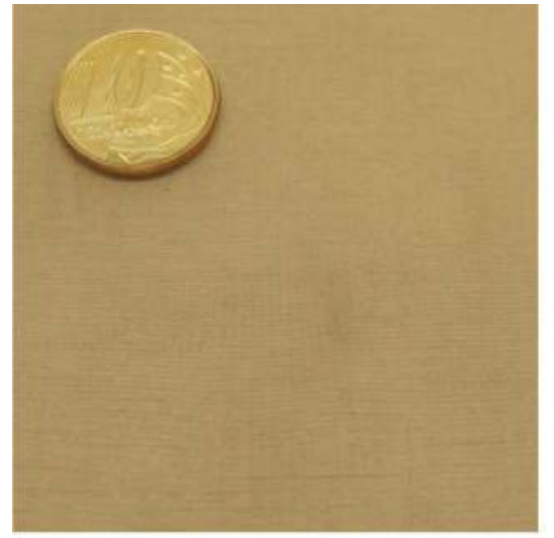

(a)

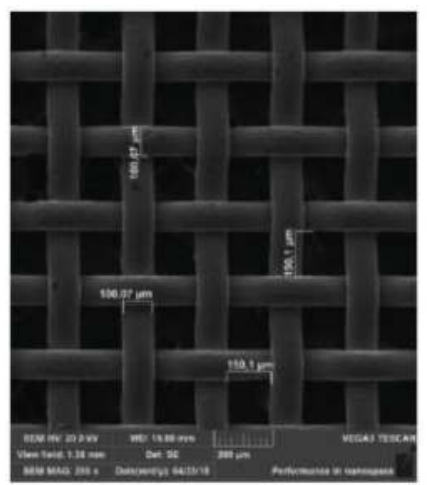

(b)

Figure 10. Phosphor bronze screen mesh \#100. (a) General view (b) micro-scale image. 
in length, an adiabatic region of $20 \mathrm{~mm}$ in length, and a condenser of $100 \mathrm{~mm}$ in length. The working fluid used is distilled water with filling ratios related to the evaporator volume based on the best performance of each capillary structure. Table $\mathbf{1}$ shows the main characteristics of the heat transfer passive devices analyzed in this research.

The mesh heat pipe used one layer of phosphor bronze screen mesh \#100 (Figure 10a) as capillary structure. A microscale image of screen mesh \#100 is shown in Figure 10b. The image was obtained by backscattered electron detector (BSD) for scanning electron microscope (SEM). More information about this mesh heat pipe can be found in [23].

The grooved heat pipe shown schematically in Figure 11a had 32 microgrooves made by the wire electrical discharge machining (wire-EDM). Figure $\mathbf{1 1 b}$ presents the axial microgrooves details with an average diameter of $220 \mu \mathrm{m}$ by a micro-scale image. The image was obtained by backscattered electron detector (BSD) for scanning electron microscope (SEM). More details about this heat pipe can be found in [24, 28].

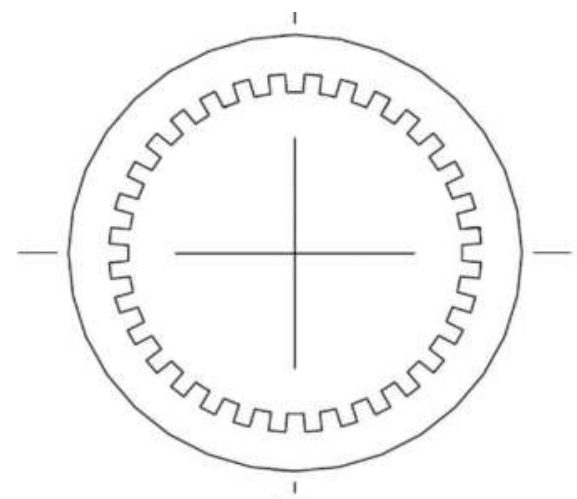

(a)

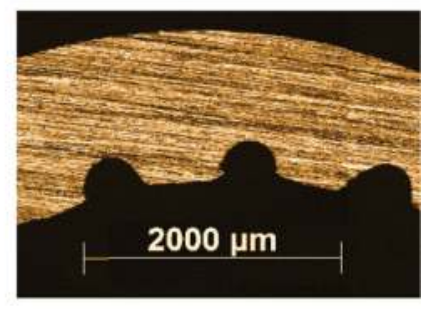

(b)

Figure 11. Microgrooves made by wire-EDM. (a) Scheme of microgroove profile and (b) microscale image.

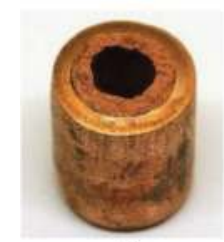

(a)

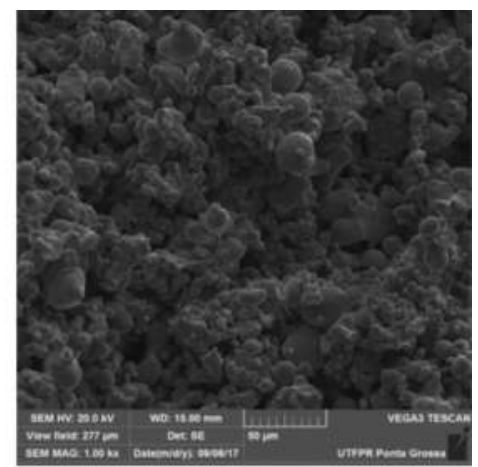

(b)

Figure 12. Structure sintered copper powder. (a) General view and (b) microscale image. 
The sintered heat pipe was produced by the sintering process with a copper powder and a temporary mandrel. The average diameter of the copper powder particle is $10.9 \mu \mathrm{m}$. The porous structure manufactured has a thickness of $1.5 \mathrm{~mm}$ (Figure 12a). The microscale image of the capillary structure of sintered copper powder is presented in Figure 12b. More information about this sintered heat pipe can be found in [26].

\section{Experimental tests}

To achieve successful results, the experimental tests must reproduce the operation conditions as close as possible to the application for thermal management of thermoelectric cooling. Then, to evaluate the thermal performance of the analyzed passive heat transfer devices, an experimental apparatus and some experimental procedures were used.

\subsection{Experimental apparatus}

The essential experimental apparatus for the experimental tests, shown in Figure 13, is composed of a data logger (Agilent ${ }^{\mathrm{TM}} 34970 \mathrm{~A}$ with 20 channels), a power supply unit (Keysight ${ }^{\mathrm{TM}}$ $\mathrm{U} 8002 \mathrm{~A})$, a laptop (Dell $\left.\mathrm{TM}^{\mathrm{M}}\right)$, an uninterruptible power supply $\left(\mathrm{NH} \mathrm{S}^{\mathrm{TM}}\right)$, a universal support, and a fan (Ultrar $\left.{ }^{\mathrm{TM}}\right)$.

For the evaluation of the temperature of the different heat transfer passive devices, K-type thermocouples Omega Engineering ${ }^{\mathrm{TM}}$ are used. They should be fixed on the outer surface of devices by a thermosensitive adhesive strip Kapton ${ }^{\mathrm{TM}}$. They should be distributed in the length of the heat pipes and thermosyphon. Thus, there are three thermocouples in the evaporator $\left(T_{\text {evap }, 1^{\prime}}, T_{\text {evap }, 2^{\prime}}\right.$ and $\left.T_{\text {evan }, 3}\right)$, one thermocouple in the adiabatic section $\left(T_{\text {adiaa }}\right)$ e four thermocouples in the condenser $\left(T_{\text {cond }, 1^{\prime}}, T_{\text {cond }, 2}, T_{\text {cond }, 3^{\prime}}\right.$ and $\left.T_{\text {cond }, 4}\right)$ in passive devices (heat pipes and thermosyphon), as shown in Figure 14. For the rod, two thermocouples were fixed in the evaporator

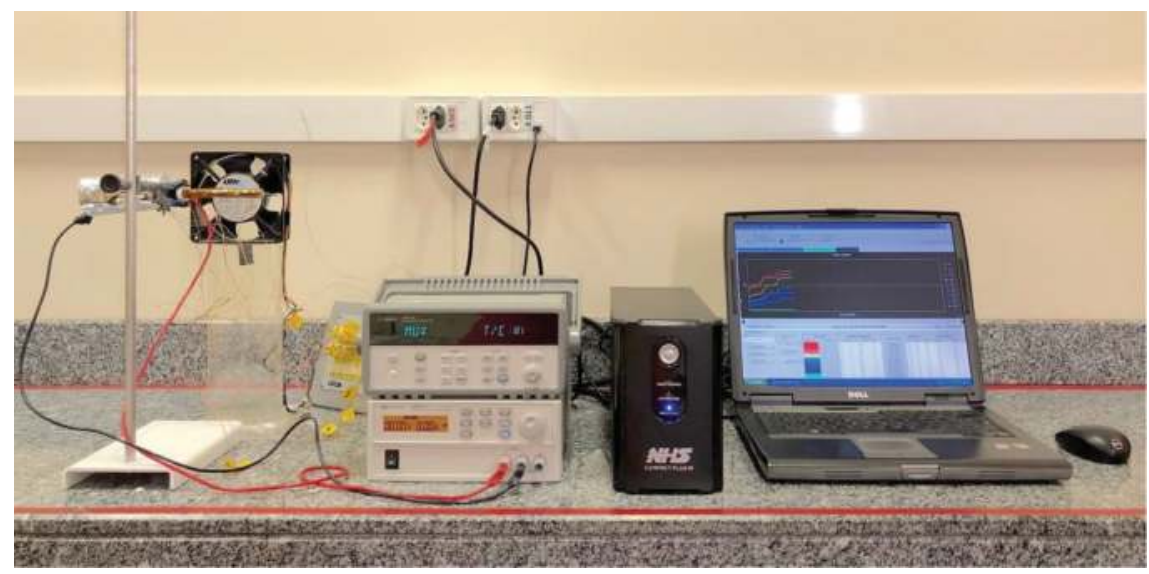

Figure 13. Experimental apparatus. 


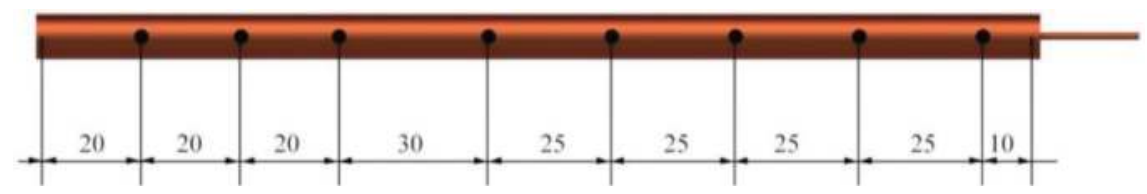

Figure 14. Thermocouple positions in heat pipes.

( $T_{\text {evap }, 1}$ and $\left.T_{\text {evap }, 2}\right)$, one thermocouple in the adiabatic section $\left(T_{\text {adiab }}\right)$ and three thermocouples in the condenser $\left(T_{\text {cond }, 1}, T_{\text {cond }, 2^{\prime}}\right.$ and $\left.T_{\text {cond }, 3}\right)$.

As is already known, for the correct operation of the heat pipe and thermosyphon, a heating system is needed in the evaporator and a cooling system in the condenser. The evaporator can be power dissipation in any kind of resistor (strip, cartridge) or a heat source, as the TEC hot side. The cooling system can consist of forced convection by air, water, or coolant, in most of the cases. The adiabatic section may have variable dimensions (in some cases, it is absent) and should be insulated from the external environment.

Thus, in this research, the heating system of the evaporator is conducted by power dissipation from the passage of an electric current in a nickel-chromium alloy power strip resistor Omega Engineering ${ }^{\mathrm{TM}}$ with $0.1 \mathrm{~mm}$ of thickness and $3.5 \mathrm{~mm}$ of width. To ensure that the generated heat by Joule effect is transmitted to the evaporator, an aeronautic thermal insulation and a layer of polyethylene are installed in this region. A fiberglass tape is used in adiabatic section as heat insulation between the support and the passive device. The cooling system using air forced convection consisted of a fan in the condenser region.

\subsection{Experimental procedure}

To ensure the best results and the repeatability of experimental tests, the environment temperature was maintained at $20^{\circ} \mathrm{C} \pm 0.5^{\circ} \mathrm{C}$. A thermal conditioning system Carrier ${ }^{\mathrm{TM}}$ was used for this purpose. A detailed check of the equipment and the heat pipe or thermosyphon (fixing thermocouples, thermal insulation, resistor connection, among others) must be made before each experimental test. The heat pipe or thermosyphon was carefully fixed to the universal support bracket in the adiabatic region in the desired position. The cooling system was turned on in the condenser region and set at a speed of $5 \mathrm{~m} / \mathrm{s}$ controlled by a potentiometer with a combined error of $\pm 0.2 \mathrm{~m} / \mathrm{s}$. The data acquisition system was turned on, collecting the temperatures measured by the K-type thermocouples. The temperatures should be verified according to the environment temperature, and if these were stable and approximately $20^{\circ} \mathrm{C}$, finally, the heating system can be turned on and adjusted to the dissipation power desired. The initial load was $5 \mathrm{~W}$ and, after approximately $15 \mathrm{~min}$, the thermocouples showed stationary values. If it happened, the thermal load has been increased by $5 \mathrm{~W}$. The load increment was made until the maximum temperature of the device reached the critical temperature $\left(150^{\circ} \mathrm{C}\right)$, where the melting of the materials could happen. Data were acquired every $5 \mathrm{~s}$, recorded on the desktop by the software Agilent ${ }^{\mathrm{TM}}$ Benchlink Data Logger 3. 


\section{Data reduction}

\subsection{Thermal parameters}

The thermal performance of the heat pipes and the thermosyphon was analyzed and compared by the operating temperatures $\left(T_{o p}\right)$, the global thermal resistance $\left(R_{t h}\right)$, and the effective thermal conductivity $\left(k_{\text {eff }}\right)$. The analyzed operating temperature is the temperature of the adiabatic region. The global thermal resistance, $R_{t h^{\prime}}$ of a heat pipe and a thermosyphon can be defined as the difficulty of the passive device to transport the heat power and can be calculated by:

$$
R_{\text {th }}=\frac{\Delta T}{q}=\frac{\left(T_{\text {evup }}-T_{\text {cond }}\right)}{q}
$$

where, $q$ is the heat transfer capability of the device, $T_{\text {evap }}$ and $T_{\text {cond }}$ are the mean temperature of the evaporator and the condenser, respectively.

The effective thermal conductivity, $k_{\text {eff }}$ is the property of a certain material to conduct heat. Defined by:

$$
k_{e f f}=\frac{q L_{e f f}}{A_{C} \Delta T}=\frac{q L_{e f f}}{A_{C}\left(T_{\text {evap }}-T_{\text {cond }}\right)}
$$

where, $L_{e f f}$ is the effective length and $A_{C}$ is the heat transfer cross-sectional area. The effective length can be defined by:

$$
L_{\text {eff }}=\frac{L_{\text {evap }}}{2}+L_{\text {adiab }}+\frac{L_{\text {cond }}}{2}
$$

where, $L_{\text {evap }}$ is the evaporator length, $L_{\text {adiab }}$ is the adiabatic section length, and $L_{\text {cond }}$ is the condenser length.

The heat transfer cross-sectional area can be defined by:

$$
A_{C}=\frac{\left(\pi D_{i}^{2}\right)}{4}
$$

where $D_{i}$ is the inner diameter of the heat transfer passive device.

\subsection{Uncertainties analysis}

In general, the experimental uncertainties are associated to the K-type thermocouples, the data logger, and the power supply unit. The experimental measurement uncertainties were analyzed using the uncertainty combination method described in [29] considering the combination of uncertainties of correlated quantities. They are shown in the obtained 
results. It is known that the accuracy of the thermocouples is $\pm 2.2^{\circ} \mathrm{C}$ and the uncertainty was evaluated as the rectangle type. Thus, the uncertainty values of the temperature sensors were estimated in:

$$
u(T)=\frac{ \pm 2,2}{\sqrt{3}}= \pm 1,27^{\circ} \mathrm{C}
$$

The combined uncertainties of the evaporator, adiabatic section, and condenser temperatures were calculated according to the following equations respectively:

$$
\begin{gathered}
u\left(T_{\text {evap }}\right)=\left|\frac{\partial T_{\text {evap }}}{\partial T_{\text {evap }, 1}}\right| u\left(T_{\text {evap }, 1}\right)+\left|\frac{\partial T_{\text {evap }}}{\partial T_{\text {evap }, 2} \mid}\right| u\left(T_{\text {evap }, 2}\right)+\left|\frac{\partial T_{\text {evap }}}{\partial T_{\text {evap }, 3} \mid}\right| u\left(T_{\text {evap }, 3}\right) \\
u\left(T_{\text {adiab }}\right)=u(T)= \pm 1,27^{\circ} \mathrm{C} \\
u\left(T_{\text {cond }}\right)=\left|\frac{\partial T_{\text {cond }}}{\partial T_{\text {cond, }, 1}}\right| u\left(T_{\text {cond }, 1}\right)+\left|\frac{\partial T_{\text {cond }}}{\partial T_{\text {cond }, 2}}\right| u\left(T_{\text {cond }, 2}\right)+\left|\frac{\partial T_{\text {cond }}}{\partial T_{\text {cond }, 3}}\right| u\left(T_{\text {cond }, 3}\right)+\left|\frac{\partial T_{\text {cond }}}{\partial T_{\text {cond }, 4}}\right| u\left(T_{\text {cond }, 4}\right)
\end{gathered}
$$

The measurement uncertainties associated with the dissipated power in the evaporator were estimated according to the power supply in the electrical resistance of the tests. The uncertainties were evaluated as the rectangle type, considering the voltage accuracy of $0.35 \%+20 \mathrm{mV}$ and the current accuracy of $0.35 \%+20 \mathrm{~mA}$. The electrical power dissipated by the electric resistance, $P$, is calculated as shown below:

$$
P=V I
$$

where $V$ is the voltage and $I$ is the current.

Considering that thermal losses in the evaporator region are negligible and that all energy is transferred to the wall of the heat pipe, the uncertainty of the heat transfer capacity can be estimated as:

$$
u(q)=u(P)=\left|\frac{\partial q}{\partial V}\right| u(V)+\left|\frac{\partial q}{\partial I}\right| u(I)
$$

The global thermal resistance uncertainty can be calculated by the following equation:

$$
u\left(R_{t h}\right)=\left|\frac{\partial R_{t h}}{\partial q}\right| u(q)+\left|\frac{\partial R_{t h}}{\partial \Delta T}\right| u(\Delta T)
$$

where the uncertainty of the temperature difference can be defined as:

$$
u(\Delta T)=\left|\frac{\partial \Delta T}{\partial T_{\text {evap }}}\right| u\left(T_{\text {evap }}\right)+\left|\frac{\partial \Delta T}{\partial T_{\text {cond }}}\right| u\left(T_{\text {cond }}\right)
$$




\section{Evaluation of the thermal performance}

To summarize the analysis of the thermal performance of the heat pipes and the thermosyphon, different types of passive heat transfer devices were experimentally evaluated and compared. The considered devices were a rod, a thermosyphon, a mesh heat pipe, a grooved heat pipe, and a sintered heat pipe. The analyzed operating positions were vertical and horizontal. The experimental tests were repeated three times and the errors were compared taking into account the difference between the mean values less than $0.5^{\circ} \mathrm{C}$. The tests were performed at increasing heat loads of $5 \mathrm{~W}$, ranging from 5 to $45 \mathrm{~W}$ for both positions.

\subsection{Temperature distribution}

Figure 15 shows the temperature distributions as a function of time for the heat pipe with axial microgrooves in the vertical position. The heat pipe starts to work at a temperature of $44^{\circ}$ $\mathrm{C}$, for a heat load of $5 \mathrm{~W}$. The maximum dissipated power of the grooved heat pipe was $45 \mathrm{~W}$. Figure 16 presents the temperature distribution in function of the thermocouple position in the heat pipe length for different heat loads.

\subsection{Operation temperature}

The behavior of the operating temperature as a function of the dissipated power for different passive devices is shown in Figure 17. It may be noted that as the dissipated power increases, the operating temperature also increases for all the devices in both positions.

\subsection{Global thermal resistance}

Figure 18 presents the global thermal resistance as a function of the power dissipation considering the rod, the thermosyphon, and the heat pipes. The results of two operating positions

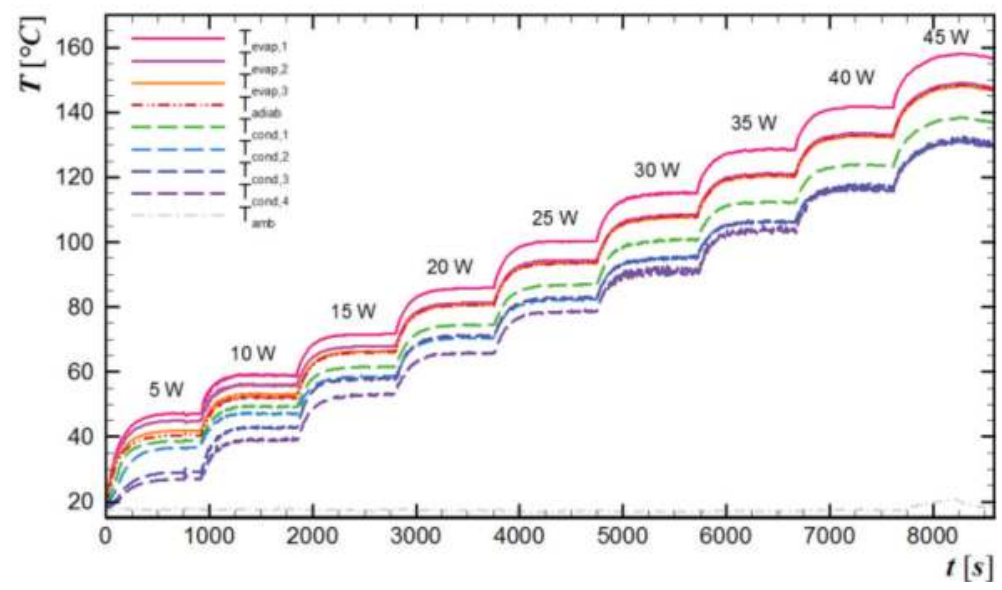

Figure 15. Temperature distribution versus time: Grooved heat pipe in vertical. 


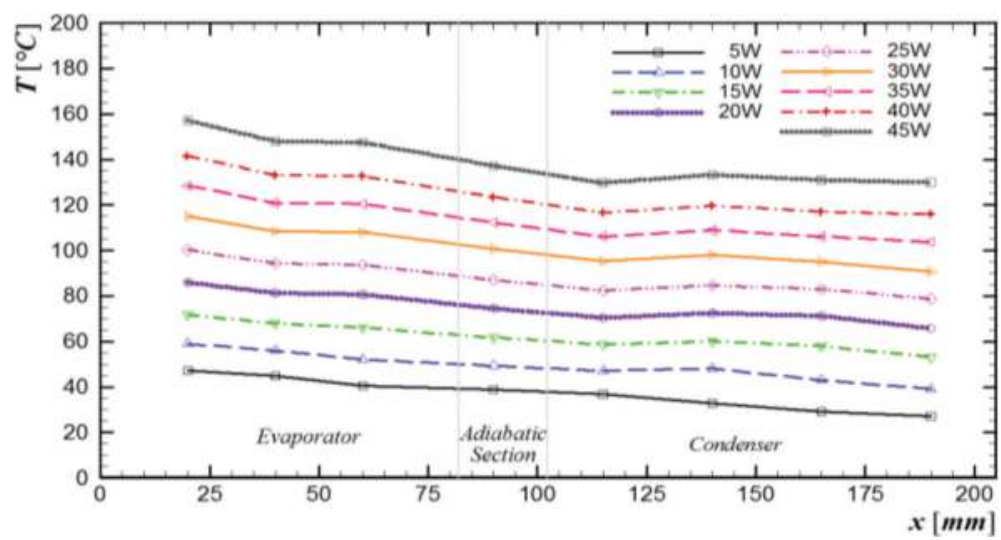

Figure 16. Temperature distribution versus thermocouple position: Grooved heat pipe in vertical.

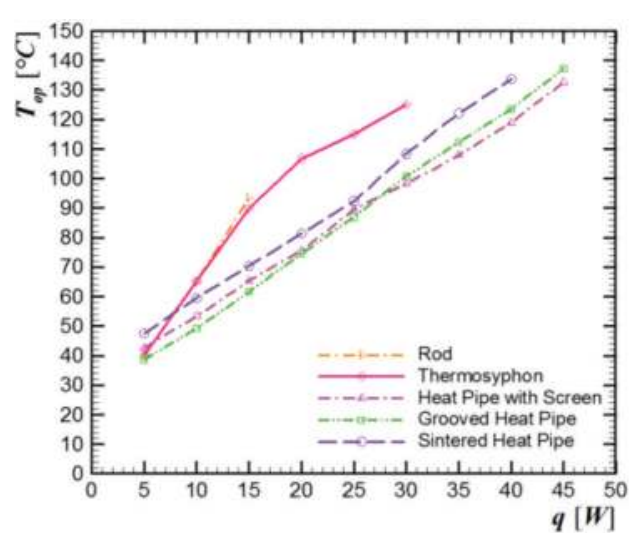

(a)

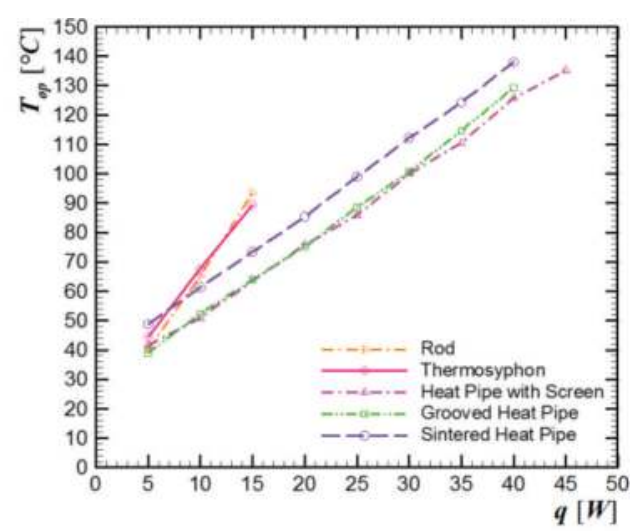

(b)

Figure 17. Operating temperature versus power dissipation. (a) Vertical and (b) horizontal.

are compared. As the heat dissipation is increased, the thermal resistance decreases for the thermosyphon and the heat pipes in the vertical position. In horizontal, the heat pipes obtain the same behavior; however, the thermosyphon has changed dramatically. It happens due to the necessity of gravity for the fluid return in the thermosyphon. The rod thermal resistance remains almost constant for the entire heat loads in both positions.

As mentioned, the global thermal resistance of the heat pipes and the thermosyphon take into consideration the temperature difference between the evaporator and the condenser and, the dissipated power. However, the processes governing the global thermal resistance are related to the fluid dynamics and the heat transfer. The fluid dynamics is influenced by the gravity and the capillary pumping. In the thermosyphon, the fluid flow from the condenser to the evaporator occurs exclusively by gravity. On the other hand, 
in the heat pipes, besides gravity, the capillary pumping also has a positive influence on the fluid flow. The heat transfer in the evaporators is governed by boiling, which is facilitated due to the existence of nucleation sites. Thermosyphon nucleation sites happen due to the surface roughness (imperfections). In the heat pipes, the capillary structures (screen meshes, microgrooves, or sintered media) provide the nucleation sites, making the boiling process more efficient. Thus, according to Figure 18, the global thermal resistance of the heat pipes is lower than the rod and the thermosyphon. This can be explained by the influence of gravity and the capillary pumping. Also, the boiling process is more efficient due to the existence of more nucleation sites. Finally, note that values of global thermal resistance could be lower if the overall heat transfer coefficient in the condenser of the passive devices were higher, which could be achieved, for example, using fins or liquid cooling.
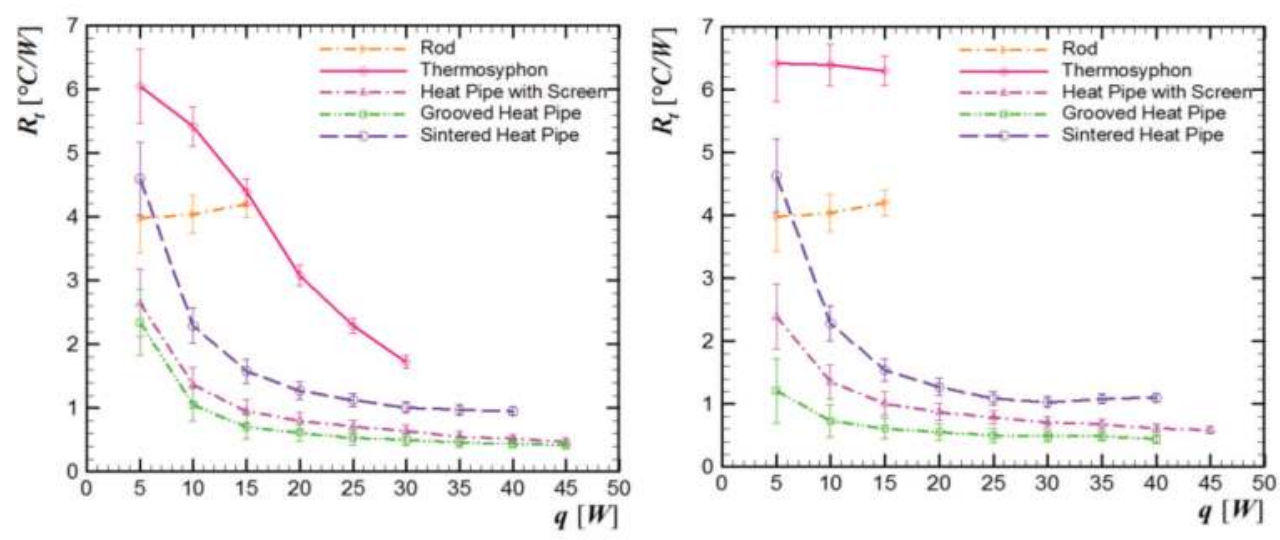

Figure 18. Thermal resistance versus power dissipation. (a) Vertical and (b) horizontal.
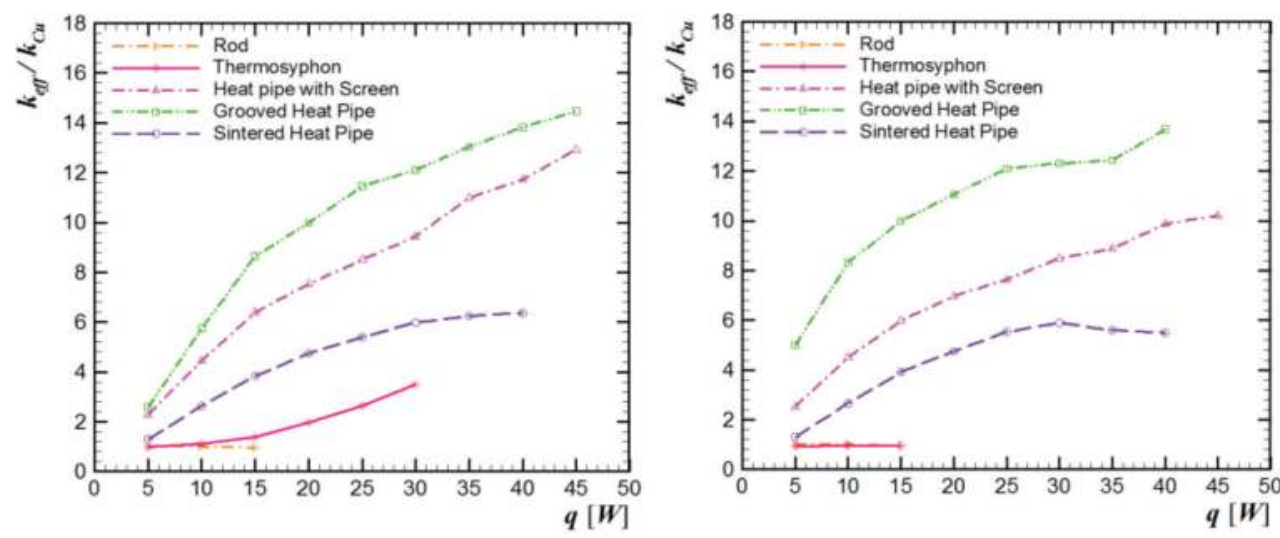

Figure 19. Effective thermal conductivity versus power dissipation. (a) Vertical and (b) horizontal. 


\subsection{Effective thermal conductivity}

In Figure 19, the behavior of the effective thermal conductivity of the passive heat transfer devices is shown as a function of the power dissipated for vertical (a) and horizontal (b) positions. As expected, it can be seen that the passive devices that use phase change (heat pipes and thermosyphon) have a higher effective thermal conductivity and that this parameter increases with increasing power dissipation.

\section{Conclusions}

In this research, each step of the heat pipes and the thermosyphon manufacturing (cleaning, assembly, tightness test, evacuation procedure, and filling with the working fluid) was described in detail. The proposed procedure has low-cost and the heat transfer passive devices are easy-to-manufacture. Then, an experimental investigation of the thermal performance of different heat transfer passive devices (solid rod, thermosyphon, mesh heat pipe, grooved heat pipe, and sintered heat pipe) was performed. These passive heat transfer devices were tested in vertical and horizontal positions under thermal loads between 5 and $45 \mathrm{~W}$ and worked satisfactorily, except rod and thermosyphon in the horizontal position. The vertical position showed better results than the horizontal one due to gravity. The thermosyphon showed a satisfactory thermal performance in the vertical position. However, in the horizontal, its behavior was worse than a rod. The heat pipes were the devices with the best thermal performance due to the use of the vaporization heat of the working fluid concurrently with the capillary structure. The grooved heat pipe had a better thermal performance based on the lower global thermal resistance or the higher effective thermal conductivity. The experimental results showed that heat pipes and thermosyphon can be successfully used in TEC hot side cooling, and due to the behavior of the global thermal resistance and the effective thermal conductivity, on the other hand, a solid rod cannot be used.

\section{Acknowledgements}

Acknowledgments are provided to the CAPES, the CNPq, the PROPPG/UTFPR, the DIRPPG/ UTFPR, the PPGEM/UTFPR/Ponta Grossa, and the DAMEC/UTFPR/Ponta Grossa.

\section{Nomenclature}

$\begin{array}{ll}A_{C} & \text { cross-sectional area, }\left[\mathrm{m}^{2}\right] \\ D_{i} & \text { inner diameter, }[\mathrm{m}] \\ I & \text { current, }[\mathrm{A}]\end{array}$




$\begin{array}{ll}k & \text { thermal conductivity, }[\mathrm{W} / \mathrm{mK}] \\ L & \text { length, }[\mathrm{m}] \\ P & \text { electrical power dissipated, [W] } \\ q & \text { heat transfer rate, }[\mathrm{W}] \\ R_{\text {th }} & \text { total thermal resistance, }\left[{ }^{\circ} \mathrm{C} / \mathrm{W}\right] \\ t & \text { time, }[\mathrm{s}] \\ T & \text { temperature, }\left[{ }^{\circ} \mathrm{C}\right] \\ V & \text { voltage, }[\mathrm{V}] \\ \text { Subscripts } & \\ \text { adiab } & \text { adiabatic section } \\ \text { Cu } & \text { copper } \\ \text { cond } & \text { condenser } \\ \text { eff } & \text { effective } \\ \text { evap } & \text { evaporator }\end{array}$

\section{Author details}

Thiago Antonini Alves*, Larissa Krambeck and Paulo H. Dias dos Santos

*Address all correspondence to: thiagoaalves@utfpr.edu.br

Federal University of Technology, Parana, Brazil

\section{References}

[1] Antonini Alves T, Altemani CAC. An invariant descriptor for heaters temperature prediction in conjugate cooling. International Journal of Thermal Sciences. 2012;58:92-101. DOI: 10.1016/j.ijthermalsci.2012.03.007

[2] Nishida FB, Tadano YS, Antonini AT. Conjugate forced convection-conduction heat transfer in channel flow using different cooling fluids. In: Proceedings of the 15th International Heat Transfer Conference (IHTC-15); 10-15 August 2014; Kyoto/JAP. Connecticut/USA: Begell House; 2014. IHTC15-9594, p. 1957-1970. DOI: 10.1615/IHTC15.eec.009594

[3] Krambeck L, Nishida FB, Aguiar VM, Santos PHD, Antonini Alves T. Thermal performance evaluation of different passive devices for electronics cooling. Thermal Science. 2017; OnLine-First Issue00:300. DOI: 10.2298/TSCI170610300K 
[4] Sun X, Zhang L, Liao S. Performance of a thermoelectric cooling system integrated with a gravity-assisted heat pipe for cooling electronics. Applied Thermal Engineering. 2017;116:433-444. DOI: 10.1016/j.applthermaleng.2016.12.094

[5] Sun X, Ling L, Liao S, Chu Y, Fan S, Mo Y. A thermoelectric cooler coupled with a gravity-assisted heat pipe: An analysis from heat pipe perspective. Energy Conversion and Management. 2018;155:230-242. DOI: 10.1016/j.enconman.2017.10.068

[6] Remeli MF, Kiatbodin L, Singh B, Verojporn K, Date A, Akbarzadeh A. Power generation from waste heat using heat pipe and thermoelectric generator. Energy Procedia. 2015;75:645-650. DOI: 10.1016/j.egypro.2015.07.477

[7] Faghri A. Heat pipes: Review, opportunities and challenges. Frontiers in Heat Pipes. 2014; 5:01-48. DOI: 10.5098/fhp.5.1

[8] Reay DA, Kew PA, McGlen RJ. Heat Pipe: Theory, Design and Applications. 6th ed. Amsterdam/NED: Butterworth-Heinemann; 2014. p. 288

[9] Mantelli MBH. Thermosyphon technology for industrial applications. In: Vasiliev LL, Kakaç S, editors. Heat Pipes and Solid Sorption Transformations. 1st ed. Boca Raton/ USA: CRC Press; 2013. pp. 411-464

[10] Groll M, Rösler S. Operation principles and performance of heat pipes and closed twophase thermosyphons. Journal of Non-Equilibrium Thermodynamics. 1992;17:091-151

[11] Santos PHD, Reis LS, Marquardt LS, Vicence KAT, Alves A. T. Modeling and experimental tests of a copper thermosyphon. Acta Scientiarum Technology. 2017;39:59-68. DOI: 10.4025/actascitechnol.v39i1.28957

[12] Santos DLF, Marquardt LS, Santos PHD, Antonini AT. Metallic mesh as capillary structure applied in heat pipe heat exchanger for heat recovery. Advanced Materials Research. 2014;1082:309-314. DOI: 10.4028/www.scientific.net/AMR.1082.309

[13] Vasiliev LL. Micro and miniature heat pipes - Electronic component coolers. Applied Thermal Engineering. 2006;28:266-273. DOI: 10.1016/j.applthermaleng.2006.02.023

[14] Krambeck L, Nishida FB, Santos PHD, Antonini AT. Configurations of phosphor bronze meshes in heat pipes: An experimental analysis of thermal performance. International Journal of Advanced Engineering Research and Science. 2015;2:11-14

[15] Nishida FB, Marquardt LS, Borges VYS, Santos PHD, Antonini Alves T. Development of a copper heat pipe with axial grooves manufactured using wire electrical discharge machining (wire-EDM). Advanced Materials Research. 2015;1120-1121:1325-1329. DOI: 10.4028/www.scientific.net/AMR.1120-1121.1325

[16] Webb RL. Next generation devices for electronic cooling with heat rejection to air. Journal of Heat Transfer. 2005;127:2-10. DOI: 10.1115/1.1800512

[17] Aguiar VM, Bartmeyer GA, Krambeck L, Santos PHD, Antonini Alves T. Thermal analysis of a finned thermosyphon for heat exchanger applications. International Journal of Science and Advanced Technology. 2018;5:18-21. DOI: 10.22161/ijaers.5.1.4 
[18] Remeli MF, Kiatbodin L, Singh B, Verojporn K, Date A, Akbarzadeh A. Power generation waste heat using heat pipe and thermoelectric generator. Energy Procedia. 2015;75:645-650. DOI: 10.1016/j.egypro.2015.07.477

[19] Liu D, Zhao FY, Yang HX, Tang GF. Thermoelectric mini cooler coupled with micro thermosiphon for CPU cooling system. Energy. 2015;83:29-36. DOI: 10.1016/j.energy.2015. 01.098

[20] Sun X, Yang Y, Zhang H, Si H, Huang L, Liao S, Gu X. Experimental research of a thermoelectric cooling system integrated with gravity assistant heat pipe for cooling electronic devices. Energy Procedia. 2017;105:4909-4914. DOI: 10.1016/j.egypro.2017.03.975

[21] Russo GM, Krambeck L, Nishida FB, Santos PHD, Antonini AT. Thermal performance of thermosyphon for different working fluids. Engenharia Térmica. 2015;15:03-08

[22] Aguiar VM. Influence of filling ratio and inclination angle on thermal performance of thermosyphons (in Portuguese). Ponta Grossa/BRA: Federal University of Technology - Parana; 2016

[23] Krambeck L. Experimental investigation of wire mesh thermal performance in heat pipes (in Portuguese). Ponta Grossa/BRA: Federal University of Technology - Parana; 2016

[24] Nishida FB. Development of heat pipes with microgrooves fabricated by wire electrical discharge machining (in Portuguese) [dissertation]. Ponta Grossa/BRA: Federal University of Technology - Parana; 2016

[25] Santo ME. Experimental analysis of different thermosyphon configurations for solar collector application (in Portuguese) [dissertation]. Ponta Grossa/BRA: Federal University of Technology - Parana; 2017

[26] Krambeck L, Bartmeyer GA, Fusão D, Santos PHD, Antonini AT. Experimental research of capillary structure technologies for heat pipes. In: Proceedings of the 24th ABCM International Congress of Mechanical Engineering (COBEM 2017); 3-8 December 2017; Curitiba/BRA; 2017. COBEM-2017-1170

[27] Santos PHD, Krambeck L, Antonini AT. Experimental analysis of a stainless steel heat pipe. International Journal of Science and Advanced Technology. 2014;4:17-22

[28] Krambeck L, Nishida FB, Santos PHD, Antonini AT. Heat pipe with axial microgrooves fabricated by wire electrical discharge machining (wire-EDM). In: Proceedings of the 9th World Conference on Experimental Heat Transfer, Fluid Mechanics and Thermodynamics (ExHFC-9); 11-15 June 2017; Foz do Iguaçu/BRA. 2017. PT80

[29] Holman JP. Experimental Methods for Engineers. 8th ed. New York/USA: McGraw-Hill; 2011. p. 768 
